\title{
Resistência da soja à ferrugem-asiática avaliada pela análise da produtividade de grãos
}

\author{
Wilmar Ferreira Lima ${ }^{1}$, Cássio Egídio Cavenaghi Prete ${ }^{1}$, Aliny Simony Ribeiro ${ }^{2}$ e José Francisco Ferraz de Toledo ${ }^{3}$
}

${ }^{1}$ Professores Universidade Estadual de Londrina, Departamento de Agronomia - Cx. Postal 6001, Londrina, PR. CEP: 86051-990. E-mail: wilmar.fl@uel.br, cassio@uel.br. ${ }^{2}$ Pós doutorada, bolsista do CNPq, Embrapa soja. Caixa Postal 231, CEP: 86001-970, Londrina, PR. E-mail: aliny@ cnpso.embrapa.br. ${ }^{3}$ Embrapa Soja, Caixa Postal 231, CEP: 86001-970, Londrina, PR. E-mail: jftoledo@uol.com.br.

Autor para correspondência: Wilmar Ferreira Lima (wilmar.fl@uel.br)

Data de chegada: 30/05/2011. Aceito para publicação em: 18/02/2012.

1759

\section{RESUMO}

Lima, W.F.; Prete, C.E.C.; Ribeiro, A.S.; Toledo, J.F.F. Resistência da soja à ferrugem-asiática avaliada pela análise da produtividade de grãos. Summa Phytopathologica, v.38, n.1, p.73-78, 2012.

Os objetivos desse trabalho foram estudar a resistência e/ou tolerância da soja à ferrugem-asiática, expresso por genes maiores e menores e selecionar as linhagens resistentes e/ou tolerantes mais produtivas. Foram utilizados dados de seis experimentos realizados nas safras 2005/2006, 2006/2007 e 2007/2008, em Londrina, PR, envolvendo cinco parentais e as gerações segregantes $F_{2}, F_{3}$ e $F_{4}$. Foi utilizado o delineamento inteiramente casualizado utilizando a metodologia de cultivo em covas $(01$ parcela $=01$ cova $=01$ planta $)$. Os resultados indicaram que a resistência e/ou tolerância genética à ferrugem-asiática é controlada por genes maiores e menores dispersos nos parentais que expressam ação predominantemente aditiva. Os dados também indicaram que sob pressão de inóculo é possível selecionar linhagens de soja com produtividades de grãos superiores ao parental com maior produtividade de grãos na maioria dos cruzamentos, indicando que a seleção resultou em genótipos resistentes e/ou tolerantes. A herdabilidade no sentido restrito da produtividade de grãos, na presença da ferrugem-asiática, variou de média a alta $(0,324$ a 0,815$)$ ao nível de progênies $F_{3}$, demonstrando ser possível selecionar progênies resistentes e/ou tolerantes à ferrugem-asiática já nas gerações iniciais dos programas de melhoramento.

Palavras-chave adicionais: Phakopsora pachyrhizi, Glycine max, controle genético, resistência à doença, melhoramento de soja.

\section{ABSTRACT}

Lima, W.F.; Prete, C.E.C.; Ribeiro, A.S.; Toledo, J.F.F. Resistance of soybean to Asian rust assessed by grain yield analysis. Summa Phytopathologica, v.38, n.1, p.73-78, 2012.

The main objectives of this work were to study the soybean resistance and/or tolerance to Asian rust and to select the inbred lines more productive in relation to Asian rust. Data from six experiments involving the parental lines and their $\mathrm{F}_{2}, \mathrm{~F}_{3}$ and $\mathrm{F}_{4}$ generations were used in this experiment. It was carried out in Londrina, Parana state, during the 2005/06, 2006/07 and 2007/08 cropping seasons. A completely randomized experiment with individual plants sown in hill plot was used $(01$ hill plot $=01$ plant $)$. Soybean resistance and $/$ or tolerance to Asian rust is controlled by major and minor genes expressing mainly additive effects dispersed in the parents. It is possible to select inbred lines superior to the best yielding parent from most crosses. The narrow sense heritability for the yield trait under rust pressure ranged from average to high $(0.324$ to 0.815$)$ at the $F_{3}$ progeny level, which warrants gains from selection.

Keywords: Phakopsora pachyrhizi, Glycine max, genetic control, disease resistance, soybean breeding.

A soja (Glycine max (L.) Merrill) é uma das principais culturas do Brasil. Na safra de 2010/2011 a área cultivada foi de 24,17 milhões de ha, com uma produção estimada de 72,23 milhões de toneladas (2). Em termos globais, o Brasil participa com cerca de $27,68 \%$ e $33,25 \%$, respectivamente, da produção e das exportações mundiais de soja em grão (22).

Cerca de 40 patógenos (fungos, bactérias, vírus e nematóides) atacam a soja no Brasil e as perdas anuais da produção por doenças são estimadas em cerca de $15 \%$ a $20 \%$. Entretanto, algumas doenças podem ocasionar perdas de quase $100 \%$ (3). Uma das principais doenças da soja é a ferrugem-asiática (Phakopsora pachyrhizi Syd. e P. Syd.), que causa desfolha precoce, impedindo a completa formação de grãos, com consequente redução da produtividade de grãos (3).

Os custos da ferrugem-asiática desde sua introdução no Brasil em
2001 até a safra 2008/2009 foram estimados em US\$ 11,85 bilhões, incluindo as perdas de produtividade de grãos, os custos operacionais de aplicação e os custos com fungicidas (4). Mesmo sem estimativas oficiais, o custo ferrugem deve ultrapassar os US\$16,00 bilhões até a safra 2010/11.

O uso de cultivares resistentes e/ou tolerantes é o método de controle mais eficiente e barato para os produtores, além de ser o mais adequado às práticas de conservação do ambiente. $\mathrm{O}$ estudo e o desenvolvimento de cultivares de soja com resistência à ferrugem têm focado na utilização de genes maiores $(14,11,6)$. A resistência introduzida por genes maiores, embora mais fácil e rapidamente obtida, muito provavelmente será pouco duradoura $(15,16,17)$, conforme indicam os estudos de variabilidade genética da ferrugem (10) e as quebras de resistência observadas em grande número de acessos dos 
Bancos de Germoplasma brasileiro e americano nos últimos anos. Este trabalho teve como objetivos estudar a resistência e/ou tolerância da soja à ferrugem-asiática expressa por genes maiores e menores e selecionar as linhagens mais produtivas através de experimentos realizados durante três anos em Londrina, PR.

\section{MATERIAL E MÉTODOS}

Foram conduzidos experimentos em campo, com alta pressão de ferrugem, com objetivo de discriminar genótipos quanto à resistência à ferrugem-asiática.

Cinco genótipos parentais foram utilizados nos experimentos: BRSGO 7560 (cultivar de grupo de maturação 7.5, descendente da cultivar Abura e portadora de alelo maior recessivo para resistência à ferrugem-asiática da soja, (14)); BRS 184 (cultivar de grupo de maturação 6.7, sendo portanto precoce, susceptível à ferrugem da soja); BRS 231 (cultivar de grupo de maturação 7.5, portadora de genes menores para resistência à ferrugem, (17)); BRS 232 (cultivar de grupo de maturação 7.0, susceptível à ferrugem da soja) e EMBRAPA 48 (cultivar de grupo de maturação 6.8 , susceptível à ferrugem da soja).

No ano agrícola 2005/06, além dos parentais, foi utilizada nos experimentos a geração $\mathrm{F}_{2}$ dos 10 cruzamentos dialélicos, sem recíprocos. Dois experimentos foram instalados em campo, na fazenda experimental da Embrapa Soja, em Londrina, PR, localizada a $23^{\circ}$ 22 ' de latitude sul. A semeadura do primeiro experimento ocorreu em 03/11/2005 e a do segundo em 10/11/2005. O primeiro experimento foi tratado com fungicida preventivamente e o segundo sofreu inoculações do patógeno nas bordaduras. Os parentais foram representados por 50 repetições cada um e a geração $F_{2}$ por 120 plantas (repetições) cada uma. Cada experimento foi composto por 1.450 parcelas, em delineamento inteiramente casualizado, utilizando a metodologia de cultivo em covas $(01$ parcela $=01$ cova $=01$ planta) .

No ano agrícola 2006/07, além dos cinco genótipos parentais foram incluídas as gerações $F_{2}$ e $F_{3}$ dos 10 cruzamentos entre eles, sem recíprocos. Foram semeados em dois experimentos, o primeiro tratado e o segundo não tratado com fungicidas da mesma forma que no ano anterior. Os cinco parentais foram representados por 50 repetições cada um; a geração $F_{2}$ por 160 plantas (repetições) para cada cruzamento e a geração $\mathrm{F}_{3}$ por 40 famílias com cinco plantas cada, para cada cruzamento; totalizando 3.850 parcelas por experimento. O primeiro experimento foi semeado no dia 03/ $11 / 2006$ e o segundo em 10/11/2006.

Outros dois experimentos foram instalados em campo no ano agrícola de 2007/2008. No primeiro experimento, que foi semeado no dia 30/10/2007, foram incluídos os cinco genótipos parentais e as gerações $\mathrm{F}_{4}$ dos 10 cruzamentos entre eles, sem recíprocos. Os parentais foram representados por 50 repetições cada um, a geração $\mathrm{F}_{4}$ de cada cruzamento por 50 famílias com três plantas cada, totalizando 1.750 parcelas. No segundo experimento, que foi semeado no dia 13/11/2007, foram utilizados os cinco genótipos parentais e as gerações $\mathrm{F}_{2}$ e $\mathrm{F}_{3}$ dos 10 cruzamentos entre eles, sem recíprocos. Os parentais foram representados por 50 repetições cada um; a geração $\mathrm{F}_{2}$ por 160 repetições para cada cruzamento e a geração $F_{3}$ por 40 famílias com cinco plantas cada, para cada cruzamento, totalizando 3.850 parcelas.

Os tratos culturais como: preparação do solo, adubação, controle de plantas daninhas e controle de pragas, de todos os experimentos foram semelhantes visando proporcionar pleno desenvolvimento das plantas e incluíram irrigações suplementares. A distância entre covas nas linhas úteis foi de $20 \mathrm{~cm}$ e a distância entre as linhas úteis de $1,5 \mathrm{~m}$. No intervalo entre duas linhas úteis do experimento foram semeadas duas linhas de bordadura, utilizando uma mistura de sementes remanescentes dos genótipos em experimentação. A densidade de semeadura do experimento, após a semeadura das linhas de bordadura, ficou próxima a 250.000 plantas.ha $a^{-1}$, para simular condições de cultivo de soja.

$\mathrm{O}$ inóculo da ferrugem-asiática utilizado foi multiplicado na cultivar BRSMS Bacuri, portadora de genes maiores de resistência $\left(R p p_{1}\right.$ e $\left.R p p_{3}\right)$. Os procedimentos de manutenção, coleta, preparo, concentração e aplicação do inóculo estão descritos em Ribeiro et al. (17) e Pierozzi et al. (14). A primeira inoculação ocorreu no estádio de desenvolvimento $V_{3}(5)$ e a segunda inoculação uma semana depois. Logo que foi realizada a primeira inoculação, o experimento com controle do patógeno sofreu a primeira aplicação de fungicida; no total foram feitas cinco aplicações, a intervalos aproximados de 15 dias, sendo as duas primeiras (preventivas) com o fungicida Flutriafol $(62,5 \mathrm{~g}$ i.a.ha $\left.{ }^{-1}\right)$ e as outras três com o fungicida Tebuconazole $(100 \mathrm{~g}$ i.a.ha- ${ }^{-1}$ ). Para a inoculação do patógeno utilizou-se um pulverizador manual, sendo a solução de esporos aplicada somente nas linhas de bordaduras localizadas entre as linhas úteis e ao redor do experimento. Como nos experimentos das duas safras anteriores a severidade da doença foi muito alta, em 2007/ 2008 decidiu-se fazer apenas uma inoculação com o fungo e, somente quando as plantas, de cada experimento, estivessem no estádio de desenvolvimento $\mathrm{V}_{5}$ ou $\mathrm{R}_{1}$ (5). Isto ocorreu simultaneamente nos dois experimentos e a inoculação das bordaduras ocorreu no dia 06/12/2007. Nesta safra, nos dois experimentos, não houve parcela tratada com fungicida.

Em todos os experimentos as plantas foram colhidas no estádio $\mathrm{R}_{7}$, secadas a sombra, trilhadas e pesadas individualmente. As análises das médias e variâncias dos dados de produtividade de grãos dos três anos de experimentação foram calculadas utilizando o programa computacional SGQ (Sistema de Genética Quantitativa), desenvolvido no Centro Nacional de Pesquisa de Soja (Embrapa Soja). As análises estatísticas foram feitas usando o procedimento "PROC GLM" do módulo de estatística do SAS (18).

Os parâmetros genéticos componentes das médias e variâncias foram estimados pelo teste conjunto de escala proposto por Cavalli (1) e por Hayman (7), relatados por Mather e Jinks (12). As estimativas dos parâmetros genéticos de médias e variâncias são utilizadas de forma complementar, visando facilitar a interpretação dos mecanismos genéticos que controlam a resistência da soja à ferrugem asiática. Foi utilizado o programa GENFIT (20), que utiliza o método dos quadrados mínimos ponderados. Nos procedimentos de ajuste adotou-se como correto o modelo genético mais simples, com todos os parâmetros significativamente diferentes de zero pelo teste $\mathrm{t}$ de Student ao nível de 5\% de probabilidade, e que fosse suficiente para explicar a variabilidade presente nas gerações utilizadas, isto é, quando o qui-quadrado $\left(\chi^{2}\right)$ da qualidade do ajuste do modelo fosse não significativo ao nível de $5 \%$.

O método de previsão do potencial genético de cruzamentos simples utilizado neste trabalho foi desenvolvido por Jinks e Pooni (8), utilizando-se como padrão a linhagem BRSGO 7560. A herdabilidade no sentido restrito foi estimada com base na média das progênies $F_{3}$ conforme metodologia descrita em Mather e Jinks (13). 


\section{RESULTADOS E DISCUSSÃO}

Foi observada variabilidade entre os genótipos analisados nos experimentos não tratados com fungicidas, sendo a produtividade nos experimentos do ano agrícola 2007/08 maior do que nos anos agrícolas 2005/06 e 2006/07 (Figura 1). Embora as análises de variância realizadas (dados não inclusos) tenham mostrado interação significativa entre genótipo x ano, os efeitos desta interação não foram do tipo complexo, capazes de inverter o posicionamento relativo dos genótipos (Figura 1). A maior produtividade de grãos no ano agrícola de 2007/08 sobre os demais era esperada a partir dos procedimentos experimentais adotados, pois nesse ano foi realizada apenas uma inoculação mais tardia do patógeno e, portanto, os genótipos receberam menor pressão da doença.

Os dados de severidade da ferrugem-asiática desses experimentos estão publicados $(15,16)$.

A maioria dos cruzamentos apresentou efeitos aditivos [d] significativos para as médias de todos os experimentos, corroborando as informações de Ribeiro et al. (17) (Tabela 1). O sinal de [h] presente em cinco dos dez cruzamentos foi positivo nos cruzamentos em que ocorreu, indicando dominância no sentido do aumento da produtividade de grãos. A análise desses efeitos indicou haver predominância de efeitos aditivos no controle da produtividade de grãos da soja em presença da ferrugem-asiática entre os genótipos parentais testados. Também foram observados efeitos epistáticos do tipo aditivo $\mathrm{x}$ aditivo em quatro cruzamentos, indicando que os genes em controle da produtividade de grãos interagem entre si. Observando os modelos ajustados, nota-se que em duas oportunidades o valor de [d] foi pequeno em relação ao de [h], indicando que o controle da produtividade na soja sob pressão da ferrugem asiática é realizado por vários genes dispersos nos parentais (Tabela 1).

No experimento sem tratamento com fungicida em 2006/07 foram detectados efeitos aditivos (D) ou aditivos em presença de ligação (D1 ou D2 (9)), em nove dos 10 cruzamentos realizados, indicando que os cruzamentos possuem variabilidade genética para a característica (Tabela 2). O efeito de dominância (H) foi detectado em apenas uma oportunidade, confirmando que o controle da produtividade de grãos da soja sob pressão da ferrugem é realizado principalmente por genes expressando efeitos aditivos nos genótipos testados, conforme relato de Ribeiro et al. (17). A análise da variância dos parentais indicou haver efeitos de interação genótipo x micro-ambiente, estimados como componentes de variância ambiental E1 e E2 em sete dos dez cruzamentos. Tais componentes são indicativos da existência de resposta diferenciada dos genótipos à presença do patógeno no ambiente. A análise do cruzamento BRS 184 X BRS 231 indicou que os genes menores da BRS 231 expressaram elevado grau de dominância, pois ocorreram efeitos aditivos e de dominância de médias significativos, com [h] maior que [d] e efeito de variância $\mathrm{H}$ significativo e efeito de $\mathrm{D}$ não significativo (Tabela 2).

A presença de efeitos de dominância direcional significativos no

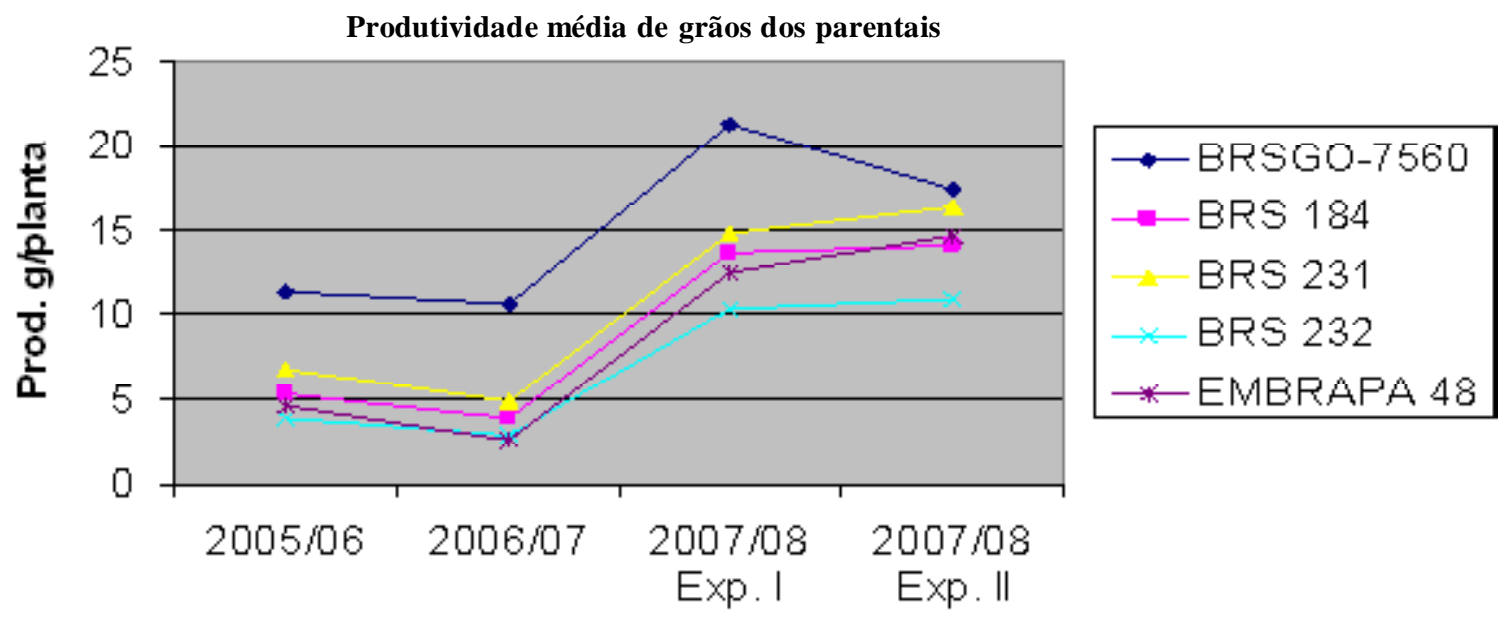

Figura 1. Produtividade média dos parentais nos experimentos não tratados com fungicidas, em Londrina, PR.

Tabela 1. Componentes genéticos de média, ajustados para o caráter produtividade de grãos, no experimento de 2006/07, não tratado com fungicidas, em Londrina, PR.

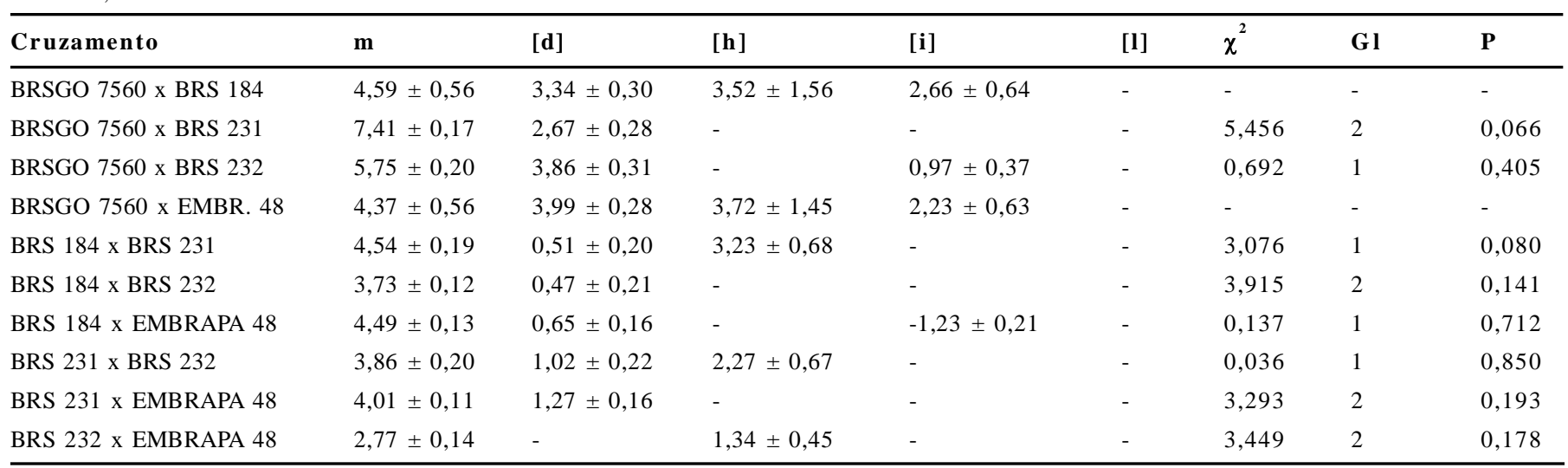


sentido de aumento da produtividade da soja na presença da ferrugem indica que durante a evolução da soja esses genes contribuíram para a sobrevivência da espécie e que, provavelmente a soja e a ferrugem conviveram no centro de origem (Tabela 2).

A probabilidade dos cruzamentos gerarem linhagens de soja superiores à produtividade média de grãos da BRSGO 7560, na presença da ferrugem-asiática (experimentos não tratados com fungicidas), está mostrada na Tabela 3. Observou-se que no experimento de 2005/06 a probabilidade de se encontrar linhagens puras superiores à BRSGO 7560 foi relativamente alta, principalmente nos cruzamentos onde ela participou. No entanto, deve-se levar em consideração também que neste experimento (2005/06) os cruzamentos são representados apenas pela geração $F_{2}$, que segundo Toledo et al. (19) prevê eficientemente híbridos de segundo ciclo e não linhagens puras. No experimento de $2007 / 08$, que inclui as gerações $\mathrm{F}_{2}$ e $\mathrm{F}_{3}$, as estimativas da probabilidade de gerar linhagens puras superiores à BRSGO 7560 foram maiores que no experimento de 2006/07, provavelmente porque no experimento de 2007/08 a pressão da doença foi menor, possibilitando a expressão de genótipos mais produtivos que a BRSGO 7560, havendo, portanto, interação genótipo $\mathrm{x}$ ambiente nesses dois experimentos. Quando se faz a análise conjunta desses dois anos, a probabilidade de se obter linhagens puras superiores ao padrão $(0,020$ a 0,320$)$ indicou ser possível selecionar linhagens superiores ao melhor parental (BRSGO 7560) e a correlação de Pearson desses dados, com os valores observados na geração $\mathrm{F}_{4}$, aumentou para 0,935 , indicando que houve sensível melhora na precisão das estimativas. Estes dados estão de acordo com os obtidos por Triller e Toledo (21), que concluíram que na presença de interação genótipo por ambiente, o uso de dados de dois ambientes foi útil para aumentar a precisão das estimativas para o caráter produtividade de grãos.

Os valores de herdabilidade no sentido restrito com base em progênies $\mathrm{F}_{3}$ foram de maneira geral médios, obviamente, superiores aos valores de herdabilidade com base em plantas $F_{3}$ (Tabela 4). Os valores de herdabilidade com base nas progênies $F_{3}$ variaram de 0,344

Tabela 2. Componentes genéticos de variância, ajustados para o caráter produtividade de grãos, no experimento de 2006/07, não tratado com fungicidas, em Londrina, PR.

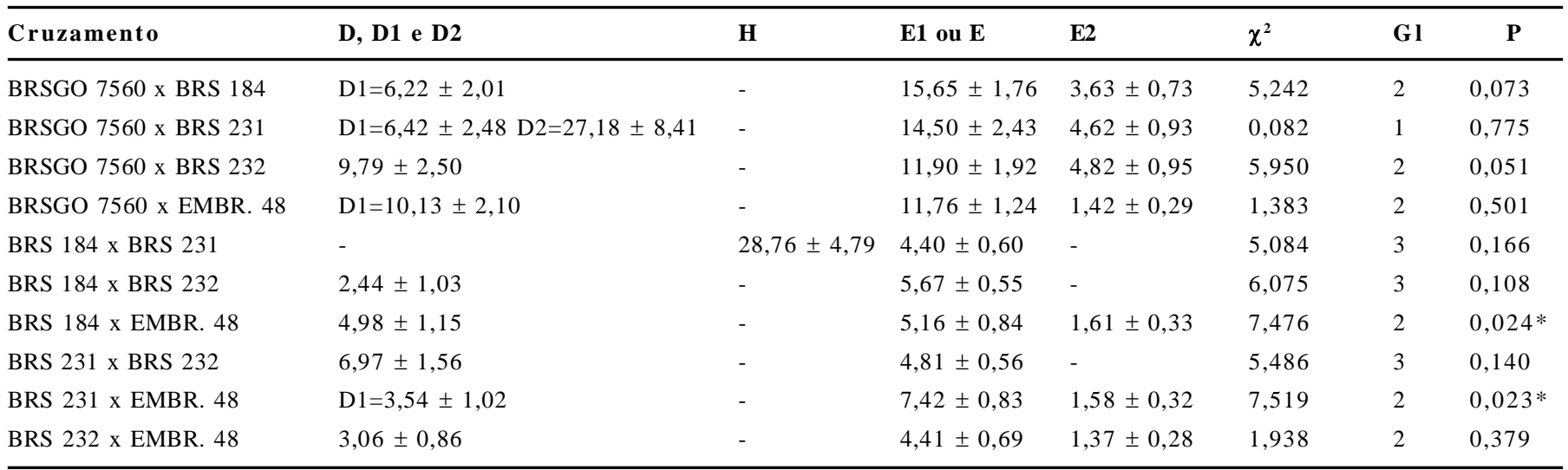

* Embora a qualidade do ajuste do modelo genético obtido através do teste Qui-quadrado $\left(\chi^{2}\right)$ ter sido significativo, optou-se por mostrá-lo, por ser o melhor modelo ajustado com os dados disponíveis. Isto ainda indica a necessidade da inclusão de outros parâmetros no modelo ajustado para explicar todos os efeitos genéticos desse cruzamento.

Tabela 3. Valores do potencial genético dos cruzamentos calculados segundo Jinks e Pooni (1976), probabilidade (P) de se obter linhagens superiores à BRSGO 7560 e correlação de Pearson dos valores estimados com os valores obtidos na geração $\mathrm{F}_{4}$, para o caráter produtividade de grãos, nos experimento de 2005/06, 2006/07 e 2007/08, não tratados com fungicidas, em Londrina, PR.

\begin{tabular}{llllll}
\hline Cruzamentos & $\begin{array}{c}\text { Estimativas } \\
\text { de } 2005 / 06\end{array}$ & $\begin{array}{l}\text { Estimativas } \\
\text { de } 2006 / 07\end{array}$ & $\begin{array}{l}\text { Estimativas } \\
\text { de } 2007 / 08\end{array}$ & $\begin{array}{c}\text { Estimativa } \\
\left.\text { 2006/07 e 2007/08( } \mathrm{F}_{2} \text { e } \mathrm{F}_{3}\right)\end{array}$ & $\begin{array}{l}\text { Valores Observados } \\
\text { em } \mathrm{F}_{4}\end{array}$ \\
\hline BRSGO 7560 x BRS 184 & $\mathbf{P}$ & $\mathbf{P}$ & $\mathbf{P}$ & $\mathbf{P}$ \\
BRSGO 7560 x BRS 231 & 0,317 & 0,011 & 0,426 & 0,320 & 0,140 \\
BRSGO 7560 x BRS 232 & 0,299 & 0,051 & 0,424 & 0,280 & 0,100 \\
BRSGO 7560 x EMB. 48 & 0,235 & 0,072 & 0,211 & $*$ & 0,100 \\
BRS 184 x BRS 231 & 0,156 & 0,018 & 0,300 & $*$ & 0,040 \\
BRS 184 x BRS 232 & 0,009 & 0,0001 & 0,142 & 0,038 & 0,020 \\
BRS 184 x EMB. 48 & 0,053 & 0,0001 & $*$ & $*$ & 0,020 \\
BRS 231 x BRS 232 & 0,100 & 0,002 & 0,253 & 0,050 & 0,020 \\
BRS 231 x EMB. 48 & 0,066 & 0,0001 & 0,272 & $*$ & 0,000 \\
BRS 232 x EMB. 48 & 0,020 & 0,0001 & $*$ & 0,020 & 0,040 \\
\hline Correlação de Pearson & 0,773 & 0,604 & 0,666 & 0,935 & 0,040 \\
\hline
\end{tabular}

* Não foi possível calcular o potencial deste cruzamento, por não ter sido possível estimar o valor de D. 
Tabela 4. Estimativa da herdabilidade no sentido restrito com base em plantas $\mathrm{F}_{3}$ e em progênies $\mathrm{F}$, para o caráter produtividade de grãos, nos experimentos de 2006/07 e 2007/08, não tratados com fungicidas, em Londrina, PR ${ }^{3}$.

\begin{tabular}{|c|c|c|c|c|}
\hline \multirow[t]{2}{*}{ Cruzamentos } & \multicolumn{2}{|c|}{$2006 / 07$} & \multicolumn{2}{|c|}{$2007 / 08$} \\
\hline & Plantas $F_{3}$ & Progênies $\mathbf{F}_{3}$ & Plantas $F_{3}$ & Progênies $F_{3}$ \\
\hline BRSGO 7560 x BRS 184 & 0,139 & 0,446 & 0,228 & 0,596 \\
\hline BRSGO $7560 \times$ BRS 231 & 0,468 & 0,815 & 0,100 & 0,357 \\
\hline BRSGO $7560 \times$ BRS 232 & 0,369 & 0,745 & 0,103 & 0,366 \\
\hline BRSGO $7560 \times$ EMB. 48 & 0,278 & 0,658 & 0,095 & 0,344 \\
\hline BRS 184 x BRS 231 & $*$ & $*$ & $*$ & $*$ \\
\hline BRS 184 x BRS 232 & 0,177 & 0,518 & 0,155 & 0,479 \\
\hline BRS 184 x EMB. 48 & 0,424 & 0,786 & $*$ & $*$ \\
\hline BRS 231 x BRS 232 & 0,420 & 0,784 & 0,219 & 0,584 \\
\hline BRS 231 x EMB. 48 & 0,164 & 0,496 & 0,148 & 0,464 \\
\hline BRS 232 x EMB. 48 & 0,346 & 0,726 & $*$ & $*$ \\
\hline
\end{tabular}

* Não foi possível calcular a herdabilidade neste cruzamento, por não ter sido possível estimar o valor de D.

a 0,815 , indicando ser possível realizar seleção para produtividade de grãos, na presença da ferrugem-asiática, já nas gerações iniciais do programa de melhoramento. Estes valores foram semelhantes aos valores de herdabilidade $(0,42$ a 0,74$)$ obtidos por Ribeiro et al. (17) (Tabela 4).

A interpretação dos resultados com base nos tipos e magnitudes dos efeitos genéticos, na probabilidade do melhorista obter genótipos superiores e na magnitude das herdabilidades no sentido restrito obtidas neste trabalho indica que um programa de melhoramento genético de soja visando à resistência e/ou tolerância à ferrugem através da combinação de genes maiores e menores tem boas chances de sucesso. Estes dados, analisados sob a ótica da experiência relatada na literatura sobre resistência e/ou tolerância a doenças em várias culturas, indicam que a seleção para produtividade da soja sob pressão de inóculo da ferrugem deve resultar em genótipos resistentes e/ou tolerantes que mantenham essas características por um período de tempo mais longo.

\section{AGRADECIMENTOS}

Os autores agradecem à FINEP e ao CNPq pelo financiamento parcial da pesquisa e pela bolsa de produtividade e pesquisa do terceiro autor.

\section{REFERÊNCIAS}

1. Cavalli, L.L. An analysis of linkage in quantitative inheritance. In: Reeve, E.C.R.; Waddington, C.D. (Eds.). Quantitative inheritance. London: HMSO, 1952. p.135-144.

2. CONAB Disponível em: <http://www.conab.gov.br/OlalaCMS/uploads/arquivos/11_04_12_11_17_51_sojaseriehist..xls >. Acesso em: 18 abril 2011.

3. EMBRAPA - Centro Nacional de Pesquisa de Soja. Tecnologias de Produção de Soja: Paraná 2007. Londrina: Embrapa Soja, p. 151 e 157, 2006.

4. EMBRAPA - Centro Nacional de Pesquisa de Soja. Consórcio antiferrugem, parceria público-privada no combate à ferrugem asiática da soja. Tabela de custos. Disponível em: <http:/ /www.consorcioantiferrugem.net/portal//wp-content/uploads/ 2010/04/tabela_custos_ferrugem-2009.pdf $>$. Acesso em: 15 setembro 2010.

5. Fehr, W.R.; Caviness, C.E.; Burmood, D.T.; Pennington, J.S. Sta- ge of development descriptions for soybeans, Glycine max (L.) Merril. Crop Science, Madison, v.11, n.6, p.929-931, 1971.

6. Garcia, A.; Calvo, E.S.; Kiihl, R.A.S.; Harada, A.; Hiromoto, D.M.; Vieira, L.G.E. Molecular mapping of soybean rust (Phakopsora pachyrhizi) resistance genes: discovery of a novel locus and alleles. Theorical and Applied Genetics, Berlin, v.117, p.545$553,2008$.

7. Hayman, B.I. Maximun likelihood estimation of genetic components of variation. Biometrics, Washington, v.16, p.369-381, 1960 .

8. Jinks, J.L.; Pooni, H.S. Predicting the properties of recombinant inbred lines derived by single seed descent. Heredity, London, v.36, n.2, p.253-266, 1976.

9. Jinks, J.L.; Pooni, H.S. Predicting the properties of pure breeding lines extractable from a cross in the presence of linkage. Heredity, London, v.49, n.3, p. 265-270, 1982.

10. Kato, M.; Yorinori, J.T. Variabilidade patogênica da Phakopsa pachyrhizi no Brasil. In: Reunião de Pesquisa de Soja da Região Central do Brasil, 28., 2006, Londrina. Anais... Londrina: Embrapa Soja/Fundação Triângulo, 2006. p. 147-149.

11. Laperuta, L. Di C.; Arias, C.A.A.; Ribeiro, A.S.; Rachid, B.F.; Pierozzi, P.H.; Toledo, J.F.F.; Pípolo. A.E.; Carneiro, G.E.S. New genes conferring resistance to Asian soybean rust: allelic testing for the $R p p 2$ and $R p p 4$ loci. Pesquisa Agropecuária Brasileira, Brasília, v.43, n.12, p.1741-1747, dez., 2008.

12. Mather, K.; Jinks, J.L. Biometrical genetics. 3. ed. London: Chapman and Hall, 1982. 396 p.

13. Mather, K.; Jinks, J.L. Introdução à genética biométrica. Ribeirão Preto: Sociedade Brasileira de Genética, 1984. 242 p.

14. Pierozzi, P.H.B.; Ribeiro, A.S.; Moreira, J.U.V.; Laperuta, L. D.C.; Rachid, B.F.; Lima, W.F.; Arias, C.A.A.; Oliveira, M.F.; Toledo, J.F.F. New soybean (Glycine Max Fabales, Fabaceae) sources of qualitative genetic resistance to Asian soybean rust caused by Phakopsora pachyrhizi (Uredinales, Phakopsoraceae). Genetics and Molecular Biology, Ribeirão Preto, v.31, n.2, p.505-511, 2008 .

15. Ribeiro, A.S.; Toledo, J.F.F.; Ramalho, M.A.P. Selection strategies of segregante soybean populations for resistance to Asian rust. Pesquisa Agropecuária Brasileira, Brasília, v.44, n.11, p.1452-1459, nov. 2009.

16. Ribeiro, A.S.; Toledo, J.F.F.; Ramalho, M.A.P. Interference of genotypes $x$ environments interation in the genetic control of resistance to Asian rust soybean. Pesquisa Agropecuária Brasileira, Brasília, v.44, n.9, p.1160-1167, set. 2009.

17. Ribeiro, A.S.; Moreira, J.U.V.; Pierozzi, P.H.B.; Rachid, B.F.; Toledo, J.F.F.; Arias, C.A.A.; Soares, R. M.; Godoy, C.V. Genetic control of Asian rust in soybean. Euphytica, Wageningen, v. 157 , n. 1-2, p.15-25, 2007. 
18. SAS INSTITUTE. SAS/STAT user's guide: statistics. 5. ed. Cary, 1990. 1686 p.

19. Toledo, J.F.F.; Pooni, H.S.; Jinks, J.L. Predicting the properties of second cycle hybrids produced by intercrossing random samples of recombinant inbred lines. Heredity, London, v.53, n.2, p.283-292, oct.1984.

20. Toledo, J.F.F. Programa de computador para estimar parâmetros genéticos, componentes de médias e variâncias, pelo método dos quadrados mínimos ponderados. Pesquisa Agropecuária Brasileira, Brasília, v.26, n.7, p.1023-1039, 1991.

21. Triller, C.; Toledo,J.F.F. Using the $\mathrm{F}_{3}$ generation for predicting the breeding potential of soybean crosses. Brazilian journal of Genetics, Ribeirão Preto, v.19, n.2, p.289-294, 1996.

22. USDA. Disponível em : < http://www.fas.usda.gov/psdonline/ psdQuery.aspx >. Acesso em: 18 abril 2011. 